(2) OPEN ACCESS

\section{Automatic oxygen titration versus constant oxygen flow rates during walking in COPD: a randomised controlled, double-blind, crossover trial}

\author{
Tessa Schneeberger, ${ }^{1,2}$ Inga Jarosch, ${ }^{1,2}$ Daniela Leitl, ${ }^{1,2}$ Rainer Gloeckl, ${ }^{1,2}$ \\ Wolfgang Hitzl, ${ }^{3,4,5}$ Clancy John Dennis, ${ }^{6}$ Tatjana Geyer, $^{7}$ Carl-Peter Criée, ${ }^{8}$ \\ Andreas Rembert Koczulla, ${ }^{1,2,9,10}$ Klaus Kenn ${ }^{1,2,9}$
}

\begin{abstract}
- Additional supplemental material is published online only. To view, please visit the journal online (http://dx.doi. org/10.1136/thoraxjnl-2020 216509)
\end{abstract}

For numbered affiliations see end of article.

\section{Correspondence to}

Tessa Schneeberger, Department of Pulmonary Rehabilitation, Philipps-University of Marburg Marburg, Hessen, Germany; TSchneeberger@schoen-klinik.

Received 2 November 2020 Accepted 5 September 2021

Check for updates

(c) Author(s) (or their employer(s)) 2021. Re-use permitted under CC BY-NC. No commercial re-use. See rights and permissions. Published by BMJ.

To cite: Schneeberger T, Jarosch I, Leitl D, et al. Thorax Epub ahead of print: [please include Day Month Year]. doi:10.1136/

thoraxinl-2020-216509

\section{ABSTRACT}

Rationale In patients with COPD, oxygen $\left(\mathrm{O}_{2}\right)$ supplementation via a constant flow oxygen system (CFOS) can result in insufficient oxygen saturation $\left(\mathrm{SpO}_{2}<90 \%\right)$ during exercise. An automatically titrating $\mathrm{O}_{2}$-system (ATOS) has been shown to be beneficial compared with an untitrated CFOS, however, it is unknown if ATOS is superior to CFOS, titrated during exercise as stipulated by guidelines. The aim was to investigate the effects of ATOS compared with titrated CFOS on walking capacity in people with hypoxaemic COPD.

Methods Fifty participants completed this prospective randomised controlled, double-blind, crossover trial. Participants performed two endurance shuttle walk tests (ESWTs) with: (1) exercise titrated CFOS (ESWT CFos $^{\text {) and }}$ (2) ATOS targeting an $\mathrm{SpO}_{2}$ of $92 \%$ (ESWT $\mathrm{ETTS}_{\text {) }}$. Primary outcome measure was walking time. Secondary measures were $\mathrm{SpO}_{2}$, transcutaneous- $\mathrm{PCO}_{2}\left(\mathrm{TCPCO}_{2}\right)$, respiratory rate (RR), heart rate (HR) at isotime (end of shortest ESWT) with blood gases and dyspnoea at rest and end exercise.

Results Participants (median (IQR): age $66(59,70)$ years, FEV $28.8(24.8,35.1) \%$ predicted, $\mathrm{PO}_{2} 54.7$ $\left.(51.0,57.7) \mathrm{mm} \mathrm{Hg}, \mathrm{PCO}_{2} 44.2(38.2,47.8) \mathrm{mm} \mathrm{Hg}\right)$ walked significantly longer with $\mathrm{ESWT}_{\text {ATOS }}$ in comparison to $\mathrm{ESWT}_{\text {CFos }}$ (median effect $(95 \% \mathrm{Cl})+144.5$ (54 to $241.5) \mathrm{s}, \mathrm{p}<0.001)$. At isotime, $\mathrm{SpO}_{2}$ was significantly higher ( $+3(95 \% \mathrm{Cl} 1$ to 4$) \%, \mathrm{p}<0.001)$ with ATOS while $\mathrm{TCPCO}_{2}, \mathrm{RR}$ and $\mathrm{HR}$ were comparable. End exercise, $\mathrm{PO}_{2}(+8.85(95 \% \mathrm{Cl} 6.35$ to 11.9$) \mathrm{mm} \mathrm{Hg})$ and dyspnoea $(-0.5(95 \% \mathrm{Cl}-1.0$ to -0.5$)$ points) differed significantly in favour of ATOS (each $p<0.001$ ) while $\mathrm{PCO}_{2}$ was comparable.

Conclusion In patients with hypoxaemia with severe COPD the use of ATOS leads to significant, clinically relevant improvements in walking endurance time, $\mathrm{SpO}_{2^{\prime}}$ $\mathrm{PO}_{2}$ and dyspnoea with no impact on $\mathrm{PCO}_{2}$.

Trial registration number NCT03803384.

\section{INTRODUCTION}

Oxygen $\left(\mathrm{O}_{2}\right)$ therapy is commonly used to treat people with hypoxic chronic obstructive pulmonary disease (COPD). ${ }^{1}$ During exercise $\mathrm{O}_{2}$ can increase $\mathrm{O}_{2}$-transport, ${ }^{2}$ delay muscle fatigue, ${ }^{2}$ alter breathing mechanics, ${ }^{3}$ reduce dyspnoea ${ }^{3}$ and improve exercise endurance. ${ }^{3}$ To be effective, prescribed flows are recommended to be titrated to an oxygen

\section{Key messages}

What is the key question?

- Does an automatic oxygen flow system perform better than a constant flow system with flows titrated for exercise as recommended by guidelines and is there an effect on carbon dioxide $\left(\mathrm{CO}_{2}\right)$ retention?

What is the bottom line?

- In patients with hypoxaemia with severe COPD the use of an automatic oxygen flow system leads to an increase in walking endurance time over the minimal important difference and despite higher oxygen $\left(\mathrm{O}_{2}\right)$-flows, has no impact on $\mathrm{PCO}_{2}$.

Why read on?

- We show that during walking exercise, despite constant flows being titrated according to guidelines, an automatically titrating oxygen system provides more $\mathrm{O}_{2}$, maintains saturation and results in greatly improved walking durations and lower dyspnoea without adversely affecting $\mathrm{CO}_{2}$.

saturation $\left(\mathrm{SpO}_{2}\right)$ of $\geq 90 \% .{ }^{4}$ However, during demanding situations like exercise, titration of $\mathrm{O}_{2}$ flow to maintain adequate $\mathrm{SpO}_{2}$ is challenging.

In practice, contrary to guidelines suggesting titration via walking test, ${ }^{25}$ exercise $\mathrm{O}_{2}$-flows are frequently titrated at rest or prescribed as a fixed addition to the titrated resting flow. ${ }^{6}$

Given this, it is common to see continuous $\mathrm{O}_{2}$ flows, while physically active, which are inadequate for varying physiological demands. ${ }^{78}$ Further, in the study setting it has been seen that a single fixed flow is insufficient in keeping adequate oxygenation in some patients with COPD. ${ }^{9}$

In clinical practice there are concerns that providing excessive $\mathrm{O}_{2}$ in patients with COPD may induce a reduction in minute ventilation and thus lead to potentially dangerous hypercapnia. ${ }^{10}$ Possibly this thinking carries over to exercise where there is a fear that using high flow rates and therefore high $\mathrm{O}_{2}$-levels in people with severe to very severe COPD may have a deleterious effect on already elevated carbon dioxide $\left(\mathrm{CO}_{2}\right)$ levels. For 
this reason it is recommended that in all patients, especially those with baseline hypercapnia, blood gases should be checked after each titration of flow for signs of respiratory acidosis and worsening hypercapnia. ${ }^{25}$

To overcome the challenge of varying metabolic demands during exercise and physical activity an automatically titrating oxygen system (ATOS), which regulates $\mathrm{O}_{2}$ flow to maintain a predefined $\mathrm{SpO}_{2}$-target, has been proposed as a solution to optimise the effects of $\mathrm{O}_{2}$-therapy. ${ }^{1}$ To date, only two studies have examined walking-exercise with ATOS in patients with COPD. These studies have shown that ATOS is better at maintaining oxygenation compared with a constant flow oxygen system (CFOS) during exercise. In general, hypoxaemia as well as hyperoxia occurred less with longer walking durations when using ATOS. These trials however had small sample sizes and were potentially biased towards ATOS as they had inappropriate $\mathrm{CFOS} \mathrm{O}_{2}$-flow rates as a control comparison, and high $\mathrm{SpO}_{2}$ targets. ${ }^{6}{ }^{21}$

Considering that ATOS can provide flows above what is normally used by patients during exercise, ATOS may exacerbate any underlying hypercapnic tendencies. Since constant blood gas monitoring in exercise is impractical, the continuous monitoring of transcutaneous carbon-dioxide partial pressure $\left(\mathrm{TcPCO}_{2}\right)$ is logical. However, to date, $\mathrm{TcPCO}_{2}$ during exercise with ATOS has not been examined. Overall, stronger evidence to support or refute the use of ATOS during exercise for people with COPD is needed. Given this, the aims of this trial were to determine, in people with COPD who were hypoxaemic at rest and/or during exercise, whether an ATOS was more effective than individually titrated CFOS at: improving endurance exercise capacity (primary outcome), oxygenation, respiratory rate, heart rate and reducing dyspnoea/leg fatigue. Additionally, $\mathrm{CO}_{2}$ levels were monitored for potential side effects of using ATOS during walking exercise.

We hypothesised that ATOS would be superior to CFOS at increasing walking exercise capacity, but with higher $\mathrm{CO}_{2}$-levels.

\section{METHODS}

This study was a prospective, single centre, randomised controlled crossover trial with blinding of participants, investigators and statistician. Randomisation of test order was achieved by an independent person prior to the study using a computer-generated random sequence. Test order was concealed in sequentially numbered sealed opaque envelopes. Participants between 40 and 80 years with a confirmed diagnosis of severe or very severe COPD (GOLD stage III to IV) with hypoxaemia or an indication for $\mathrm{O}_{2}$-therapy during exercise $\left(\mathrm{PO}_{2}<55 \mathrm{~mm} \mathrm{Hg}\right.$ at rest or during exercise or nadir $\mathrm{SpO}_{2}<88 \%$ during exercise) were recruited. Excluded were participants with an acute exacerbation of COPD or those who had cardiovascular medical conditions or orthopaedic restrictions limiting the ability to perform walking tests.

All participants were recruited and tested within an inpatient pulmonary rehabilitation programme over a period of 11 months (Schoen Klinik Berchtesgadener Land, Germany).

Informed written consent was obtained from all participants.

After an initial incremental shuttle walk test, participants performed on consecutive days (24-hour wash-out period), in a randomised order, two endurance shuttle walk tests (ESWTs) at $85 \%$ of maximum pace with ${ }^{12}:$ (1) individually titrated constant oxygen-flow rates (ESWT ${ }_{\text {CFOS }}$ ) and (2) automatically titrated oxygen-flow rates (ESWT ATOS ). The FreeO ${ }_{2}(\mathrm{OxyNov}$, Canada), is a device which uses physiological data (primarily $\mathrm{SpO}_{2}$ ) in a closed loop algorithm to control an $\mathrm{O}_{2}$-flow from 0 to $20 \mathrm{~L} / \mathrm{min}$ (flow accuracy $\pm 0.1 \mathrm{~L} / \mathrm{min}$ ) to maintain $\mathrm{SpO}_{2}$ to a predefined target. ${ }^{1314}$ The FreeO $\mathrm{O}_{2}$ can also provide a constant flow. Therefore, to blind participants and investigators, the $\mathrm{FreeO}_{2}$ device was used for both ESWTs with the display of the device covered and an independent person other than the study investigator configured the settings before the test. The FreeO $\mathrm{O}_{2}$ device, including the $\mathrm{O}_{2}$-cylinder was attached to a cart (online supplemental figure $\mathrm{S} 1$ ) and pushed by the investigator.

For the $\mathrm{ESWT}_{\mathrm{ATOS}}, \mathrm{SpO}_{2}$-target was set at $92 \%$ to maintain participants $\mathrm{SpO}_{2} \geq 90 \%$. For the ESWT exercise titrated $\mathrm{O}_{2}$-flow was used (see online supplemental for more information about $\mathrm{O}_{2}$-flow rate titration).

\section{Outcome measures}

Primary outcome was change in endurance exercise capacity as measured by ESWT. Secondary outcomes were time to $\mathrm{SpO}_{2}<90 \%$ and differences in $\mathrm{SpO}_{2}, \mathrm{TcPCO}_{2}$, heart rate (measured continuously via ear lobe sensor; SenTec, Switzerland), breathing frequency (measured continuously by respiratory inductance plethysmography; ApneaLink, ResMed, Australia) at rest, end exercise and $25 \%, 50 \%, 75 \%$ and $100 \%$ of isotime (end of shortest ESWT). $\mathrm{O}_{2}$-partial pressure, $\mathrm{CO}_{2}$-partial pressure, $\mathrm{pH}$, base excess, hydrogen carbonate, lactate (measured by blood gas analysis; RAPIDPoint, Siemens, Germany) and sensation of dyspnoea and leg fatigue (10-point Borg scale $\left.\mathrm{e}^{15}\right)$ were taken at rest and at the end of ESWTs. Blood gas samples were taken after $10 \mathrm{~min}$ at rest breathing with CFOS or ATOS and immediately at ESWT termination by an independent person.

At the end of each test, participants were asked to rate their perception of oxygenation, comfort of $\mathrm{O}_{2}$-delivery and possibility of using the $\mathrm{O}_{2}$-supplementation in everyday life on a standardised Likert-scale. Finally, after all tests, participants were asked to rate their preferred $\mathrm{O}_{2}$-system.

\section{Statistical methods}

\section{Sample size calculation}

In a retrospective study ( $\mathrm{n}=12$ patients with COPD) at our clinic, mean ESWT duration (primary endpoint) was compared in a CFOS and ATOS group. The mean difference in ESWT duration between both groups was $234.9 \mathrm{~s}$ and a SD of $392 \mathrm{~s}$. To achieve a power of $90 \%$ at a significance level of $5 \%$ in a $2 \times 2$ crossover design for testing the effect one-sided, a sample size of 50 subjects was calculated. Assuming a drop-out rate of 10\%, 55 subjects were enrolled in this study.

\section{Data analysis}

Data was checked for consistency and normality. Spearman's and Pearson's correlation coefficients were computed to analyse relations between variables. Data deviated from normality and hence non-parametric $2 \times 2$ crossover models were applied, 95\% CI for medians and median effects were computed. No carry-over effects were found in the primary outcome. Two multivariable regression models with forward and backward variable selection algorithms were set up and tested to find models with high prediction accuracy, one model to predict the $\mathrm{PCO}_{2}$ post walk in the ATOS group and another for the CFOS group. Multiple R, coefficients of determination were computed, regression coefficients were tested and residuals were analysed for normality. Observed versus predicted values were illustrated.

All reported tests were two-sided, and $\mathrm{p}$ values $<0.05$ were considered statistically significant. NCSS (NCSS 10, 


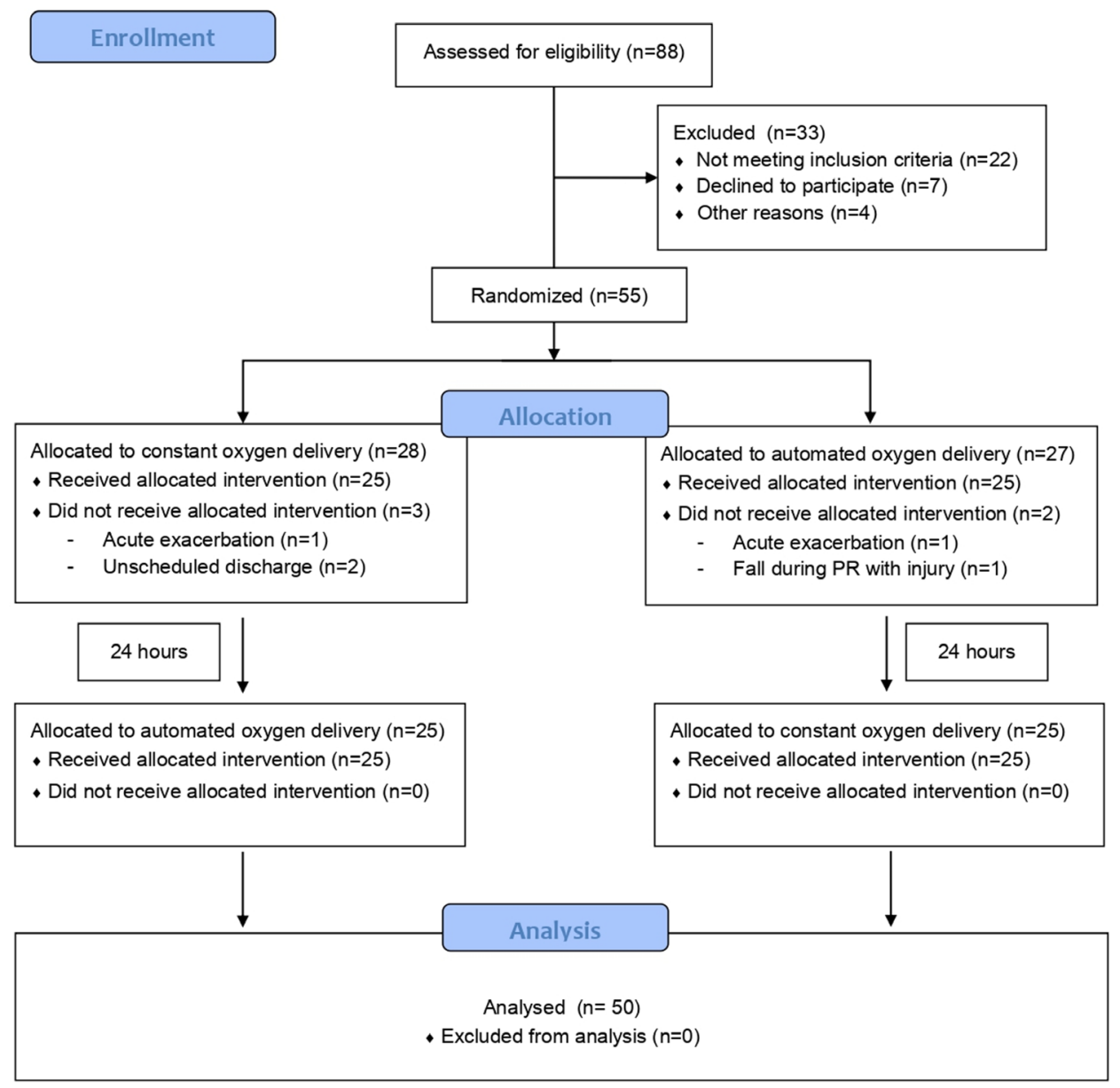

Figure 1 Consolidated Standards of Reporting Trials—flow diagram. PR, pulmonary rehabilitation.

NCSS, Kaysville, Utah, USA) and STATISTICA 13 (Hill, T. \& Lewicki, P. Statistics: Methods and Applications, StatSoft, Tulsa, Oklahoma, USA) were used to analyse data descriptively, for testing crosstabulations tables, all two-sample tests and were also used to test and illustrate multiple regression models. StatXact (2013), V.10.0.0, Cytel Software Corporation (Cambridge, Massachusetts, USA) was used for sample size computations and for testing treatment and carry-over effects in non-parametric crossover analyses. P values were computed based on Monte-Carlo simulation methods instead of using asymptotic $\mathrm{p}$ values.

PASW 24 (IBM SPSS Statistics for Windows, V.21.0.) was used to compute correlations as well as descriptive analyses.

\section{RESULTS}

\section{Trial flow and participant characteristics}

Fifty-five participants were recruited with five participants not completing the study (figure 1). All had severe to very severe COPD and were hypoxaemic (table 1). The median (IQR) pace for the ESWTs was $3.1(2.6,4.2) \mathrm{km} /$ hour. ESWT ${ }_{\text {CFOS }}$ was performed with a median $\mathrm{O}_{2}$-flow of $3 \mathrm{~L} / \mathrm{min}$ while ESWT resulted in a median flow of $4.5 \mathrm{~L} / \mathrm{min}$ (table 2 , figure $2 \mathrm{~A}$ ).

\section{Primary outcome}

Participants walked significantly $(\mathrm{p}<0.001)$ longer in ESWT $\mathrm{ATOS}_{\mathrm{AT}}$ compared with ESWT $_{\text {CFOS }}$ (table 2); 68\% $(n=34)$ of participants walked longer in ESWT ATOS, $20 \%(n=10)$ walked longer in $\mathrm{ESWT}_{\mathrm{CFOS}}$ and 12\% $(\mathrm{n}=6)$ walked equally. A longer duration than the minimal important difference (MID) of $65 \mathrm{~s}$ for an ESWT $^{12}$ was achieved by $76.5 \%(n=26 / 34)$ of participants walking longer in $\mathrm{ESWT}_{\mathrm{ATOS}}$ and $50 \%(\mathrm{n}=5 / 10)$ of those in ESWT $_{\text {CFOS }}$.

Reasons for ESWT termination significantly differed between the two tests $(p=0.001)$. Dyspnoea was reported as the main reason for stopping the ESWT in $70 \%(n=35 / 50)$ of participants with CFOS while only $48 \%(n=24 / 50)$ of the participants stopped due to breathlessness with ATOS $(\mathrm{p}=0.02)$. Participants with a higher residual volume/total lung capacity per cent predicted showed a greater rest to end exercise change in dyspnoea during walking $\left(\right.$ ESWT $_{\text {CFOS }}: \mathrm{r}=0.34, \mathrm{p}=0.01 ; \mathrm{ESWT}_{\mathrm{ATOS}}: \mathrm{r}=0.31$, $\mathrm{p}=0.03$ ) and more breathlessness at end exercise (ESWT ${ }_{\text {CFOS }}$ : $\mathrm{r}=0.43, \mathrm{p}=0.002$ ESWT $_{\text {AтоS }}: \mathrm{r}=0.40, \mathrm{p}=0.004$ ) (online supplemental figure S2 and table S1).

As a subgroup analysis, the cohort was divided into two groups: (1) ATOS responders ('participants walking $\geq$ MID (65 s) during ESWT $_{\text {Aтоs }}$ in comparison to ESWT $_{\text {CFоs }}$ ') and (2) ATOS non-responders (participants walking less than $65 \mathrm{~s}$ during the ESWT ${ }_{\text {ATOS }}$ compared with ESWT ${ }_{\text {CFOS }}$ '). Baseline characteristics were comparable. ATOS responders showed a significantly higher oxygenation and felt less breathlessness in comparison to ATOS non-responders at the end of ESWT $\mathrm{ATOS}_{\text {and received a }}$ significantly higher mean $\mathrm{O}_{2}$-flow rate during ESWT $\mathrm{ATOS}_{\text {(table 3, }}$, online supplemental figure $\mathrm{S} 3 \mathrm{~A}, \mathrm{~B})$. Respiratory rate and $\mathrm{TcPCO}_{2}$ during $\mathrm{ESWT}_{\mathrm{ATOS}}$ were comparable at each time point (online supplemental figure S3C,D), however mean $\mathrm{TcPCO}_{2}$ over the

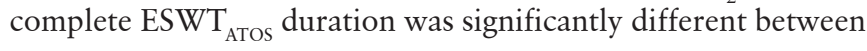




\begin{tabular}{|c|c|}
\hline Variable & COPD, $n=50$ \\
\hline Age, years & $66(59,70)$ \\
\hline Gender, female/male, n & $23 / 27$ \\
\hline $\mathrm{BMI}, \mathrm{kg} / \mathrm{m}^{2}$ & $23.9(21.3,27.0)$ \\
\hline \multicolumn{2}{|l|}{ Waist-hip ratio } \\
\hline Females & $0.89(0.83,0.94)$ \\
\hline Males & $1.0(0.94,1.04)$ \\
\hline \multicolumn{2}{|l|}{ Pulmonary function } \\
\hline $\mathrm{FEV}_{1}, \mathrm{~L}$ & $0.78(0.59,1.0)$ \\
\hline $\mathrm{FEV}_{1}, \%$ predicted & $28.8(24.8,35.1)$ \\
\hline FVC, L & $1.69(1.19,2.28)$ \\
\hline FVC, \% predicted & $50.1(41.6,63.7)$ \\
\hline $\mathrm{FEV}_{1} / \mathrm{FVC}, \%$ & $45.8(40.8,53.7)$ \\
\hline TLC, L & $7.7(7.0,9.1)$ \\
\hline TLC, \% predicted & $137.0(121.8,154.8)$ \\
\hline $\mathrm{FRC}_{\text {pleth' }} \mathrm{L}$ & $6.8(5.9,7.6)$ \\
\hline $\mathrm{FRC}_{\text {pleth }} \%$ predicted & $213.6(182.0,251.8)$ \\
\hline$R V, L$ & $5.9(5.0,7.0)$ \\
\hline RV, \% predicted & $269.9(218.1,335.6)$ \\
\hline RV/TLC, \% & $77.1(68.6,82.7)$ \\
\hline RV/TLC, \% predicted & $188.5(172.1,206.9)$ \\
\hline Raw, kPa s L ${ }^{-1}$ & $0.87(0.63,1.10)$ \\
\hline Raw, \% predicted & $289.6(209.6,367.3)$ \\
\hline sRaw, kPa s & $6.0(4.4,8.9)$ \\
\hline sRaw, \% predicted & $575.8(397.4,844.0)$ \\
\hline \multicolumn{2}{|l|}{ GOLD grade } \\
\hline III, n & $23(46)$ \\
\hline $\mathrm{IV}, \mathrm{n}$ & $27(54)$ \\
\hline
\end{tabular}

Blood gases, room air-rest

\begin{tabular}{ll}
$\mathrm{pH}$ & $7.41(7.39,7.42)$ \\
\hline $\mathrm{PO}_{2}, \mathrm{~mm} \mathrm{Hg}$ & $54.7(51.0,57.7)$ \\
\hline $\mathrm{PCO}_{2}, \mathrm{~mm} \mathrm{Hg}$ & $44.2(38.2,47.8)$ \\
\hline Exercise capacity & \\
\hline 6-minute walk distance, $\mathrm{m}$ & $303.5(245.0,371.5)$ \\
\hline 6-minute walk distance, \% predicted & $48.4(38.5,59.5)$ \\
\hline Incremental shuttle walk test, $\mathrm{m}$ & $205.0(130.0,325.0)$ \\
\hline Long-term oxygen therapy & \\
\hline Period of application, months & $47(18,79)$ \\
\hline $\mathrm{O}_{2}$-flow rates, L & \\
\hline \multicolumn{1}{|c}{ Rest } & $1.75(1.0,2.9)$ \\
\hline \multicolumn{1}{c}{ Night } & $2.0(1.0,2.9)$ \\
\hline
\end{tabular}

Data presented as median (interquartile range (IQR)) or number.

$\%$, per cent; BMI, body mass index; FEV , forced expiratory volume in $1 \mathrm{~s} ; \mathrm{FRC}$ functional residual capacity; FVC, forced vital capacity; $\mathrm{kg}$, kilograms; $\mathrm{kg} / \mathrm{m}^{2}$, kilograms per metre squared; L, litre; $\mathrm{m}$, metres; $\mathrm{mm} \mathrm{Hg}$, millimetres of mercury; $\mathrm{n}$, number; $\mathrm{PCO}_{2^{\prime}}$ partial pressure of carbon dioxide; $\mathrm{pH}$, potential of hydrogen; $\mathrm{PO}_{2}$, partial pressure of oxygen; Raw, airway resistance; RV, residual volume; sRaw, specific airway resistance; TLC, total lung capacity.

ATOS responders and non-responders: $\mathrm{TcPCO}_{2 \text { mean, }} \mathrm{mm} \mathrm{Hg} 47.1$ $(45.3,52.7)$ versus $45.0(41.6,48.8)$; median effect $(95 \% \mathrm{CI})$ $3.5 \mathrm{~mm} \mathrm{Hg}$ (0.1 to 7.1), $\mathrm{p}=0.037$.

\section{Secondary outcomes}

$\mathrm{SpO}_{2}$ was significantly higher at rest and $25 \%$ isotime with CFOS compared with ATOS, whereas at $100 \%$ isotime and at end exercise the reverse was seen (figure 2B). Time to $\mathrm{SpO}_{2}<90 \%$ was significantly shorter with ATOS (table 2).

In line with this, $\mathrm{PO}_{2}$ was significantly higher with $\mathrm{CFOS}$ at rest and significantly higher at end exercise with ATOS. Except for lactate, there was no statistical difference in $\mathrm{pH}$, base excess, hydrogen carbonate and $\mathrm{PCO}_{2}$ between the two interventions at rest and end exercise (table 2). The magnitude of change $(\Delta)$ in $\mathrm{PCO}_{2}$ from rest to end exercise varied in both tests (ESWT ${ }_{\text {CFоs: }}$ : range, -3.7 to $20.3 \mathrm{~mm} \mathrm{Hg}$; ESWT ${ }_{\text {Aтол }}$ : range, -1.7 to $19.6 \mathrm{mmHg}$ ). $62 \%$ of the participants had a comparable $\mathrm{PCO}_{2}$ response between the two ESWTs.

There was a weak to medium correlation between the mean $\mathrm{O}_{2}$-flow and the change in $\mathrm{PCO}_{2}\left(\Delta \mathrm{PCO}_{2}\right)$ during ESWT and $\mathrm{ESWT}_{\text {Aто口 }}$, independent of $\mathrm{O}_{2}$-system (ESWT ${ }_{\text {CFOS }}: \mathrm{r}=0.29$, $\mathrm{p}=0.04$; $\mathrm{ESWT}_{\text {Aтоs }}: \mathrm{r}=0.39, \mathrm{p}=0.007$; online supplemental table S2).

A multivariable regression model for $\mathrm{PCO}_{2}$ post each ESWT, based on pre walking measures, achieved a multiple correlation coefficient of $\mathrm{R}=0.78, \mathrm{R} 2=0.60 \quad\left(\mathrm{ESWT}_{\text {CFOS }}\right.$ ) and $\mathrm{R}=0.72, \mathrm{R} 2=0.52\left(\mathrm{ESWT}_{\mathrm{ATOS}}\right)$. The relation between observed and predicted variables is illustrated in figure $3 \mathrm{~A}, \mathrm{~B}$.

No differences were found for $\mathrm{TcPCO}_{2}$ at any time point between the ESWT ${ }_{\text {CFOS }}$ and ESWT $_{\text {ATOS }}$ (table 2, figure 2C). Heart rate was statistically, significantly different between the two interventions at rest, 25\%, 50\% isotime and end exercise (table 2, figure 2D). Respiratory rate differed significantly at rest and dyspnoea differed at end exercise while leg fatigue showed no difference at any time point (table 2).

When questioned, a significantly $(p=0.0005)$ higher number of participants strongly agreed that perceived oxygenation was 'satisfactory' while using ATOS $(n=28)$ in comparison to CFOS $(n=9)$. After completion of all study-related measurements a significantly $(p<0.0001)$ higher number of participants $(n=37)$ preferred ATOS over a CFOS. No other question differed significantly (online supplemental figure S4A-D).

\section{DISCUSSION}

An automatically titrating $\mathrm{O}_{2}$-system used during walking resulted in a significantly improved exercise capacity and was associated with better oxygenation and less dyspnoea at end exercise compared with a constant flow $\mathrm{O}_{2}$-system. The change in both $\mathrm{TcPCO}_{2}$ and $\mathrm{PCO}_{2}$ during walking was comparable between systems. However, significant correlations between the change in $\mathrm{PCO}_{2}$ and the mean $\mathrm{O}_{2}$-flow, independent of delivery system, were observed.

\section{Comparison to other trials}

Our results augment the data supporting the use of ATOS compared with CFOS in walking exercise by applying methodological rigour to the study design, using a robust sample size calculation, a more realistic $\mathrm{SpO}_{2}$ target for ATOS (92\% vs $\left.94 \%{ }^{6}{ }^{11} \mathrm{SpO}_{2}\right)$ and a constant flow titration during exercise (as recommended by clinical guidelines $)^{25}$ instead of a resting titration or standardised constant $\mathrm{O}_{2}$-flow (eg, resting $\mathrm{O}_{2}$-flow $+1 \mathrm{~L} / \mathrm{min}^{6} ; 2 \mathrm{~L} / \mathrm{min}_{2}{ }^{11}$ ). This is also the first trial to measure $\mathrm{CO}_{2}$-levels continuously during exercise with ATOS and the first to present an independent measurement of the partial pressure of oxygen after walking exercise. Further, this is the first time a comparison of isotime measures during the ESWT have been shown and this is also the first study to report 


\section{Table 2 Results}

\begin{tabular}{|c|c|c|c|c|}
\hline & Constant $\mathrm{O}_{2}$-flow, CFOS, $\mathrm{n}=50$ & Automatic $\mathrm{O}_{2}$-flow, ATOS, $\mathrm{n}=50$ & Pvalue ${ }^{x)}$ & Median effect $(95 \% \mathrm{Cl})$ automatic-constant \\
\hline \multicolumn{5}{|l|}{ Primary outcome } \\
\hline ESWT Time, s & $333.50(214,581)$ & $522.5(277,1200)$ & $1.203 \mathrm{E}^{-04}$ & 144.5 (54 to 241.5 ) \\
\hline \multicolumn{5}{|l|}{ Secondary outcomes } \\
\hline ESWT Distance, $\mathrm{m}$ & $310(200,620)$ & $465(200,1030)$ & $2.602 \mathrm{E}^{-04}$ & 150 (60 to 31$)$ \\
\hline Oxygen Mean $\mathrm{O}_{2}$-flow rate & $3.0(3.0,4.0)$ & $4.5(3.2,6.1)$ & $1.000 \mathrm{E}^{-05}$ & 1.34 (0.68 to 2.14$)$ \\
\hline \multicolumn{5}{|l|}{ Blood gas analyses } \\
\hline $\mathrm{PO}_{\text {2rest' }} \mathrm{mm} \mathrm{Hg}$ & $80.2(73.1,90.6)$ & $65.35(62.6,68.1)$ & $1.582 \mathrm{E}^{-14}$ & $-17.8(-22.1$ to -13.8$)$ \\
\hline $\mathrm{PO}_{2 \text { post }} \mathrm{mm} \mathrm{Hg}$ & $61.35(55.0,64.5)$ & $71.5(64.2,75.8)$ & $3.304 \mathrm{E}^{-08}$ & $8.85(6.35$ to 11.9$)$ \\
\hline $\mathrm{PCO}_{\text {2rest' }} \mathrm{mm} \mathrm{Hg}$ & $42.5(39.8,46.1)$ & $40.85(39.2,48.2)$ & 0.87 & \\
\hline $\mathrm{PCO}_{2 \text { post }} \mathrm{mm} \mathrm{Hg}$ & $50.45(46.7,54.0)$ & $50.45(46.8,54.8)$ & 0.41 & \\
\hline $\mathrm{Ph}_{\text {rest }}$ & $7.41(7.39,7.43)$ & $7.42(7.40,7.43)$ & 0.64 & \\
\hline $\mathrm{Ph}_{\text {post }}$ & $7.35(7.32,7.38)$ & $7.34(7.32,7.37)$ & 0.19 & \\
\hline $\mathrm{BE}_{\text {rest' }} \mathrm{mmol} / \mathrm{L}$ & $1.75(0.30,3.20)$ & $1.20(0.10,3.60)$ & 0.68 & \\
\hline $\mathrm{BE}_{\text {post' }} \mathrm{mmol} / \mathrm{L}$ & $0.80(-0.80,2.10)$ & $0.50(-1.10,2.40)$ & 0.52 & \\
\hline $\mathrm{HCO}_{3 \text { rest' }} \mathrm{mmol} / \mathrm{L}$ & $26.0(24.70,27.30)$ & $25.4(24.50,27,60)$ & 0.97 & \\
\hline $\mathrm{HCO}_{30 \mathrm{pos} \mathrm{t}} \mathrm{mmol} / \mathrm{L}$ & $25.0(23.60,26.10)$ & $24.80(23.40,26.50)$ & 0.78 & \\
\hline $\mathrm{S}_{\mathrm{a}} \mathrm{O}_{2 \text { rest }} \%$ & $95.0(94.60,96.60)$ & $93.08(91.70,93.50)$ & $1.582 \mathrm{E}^{-14}$ & $-3.0(-3.45$ to -2.6$)$ \\
\hline $\mathrm{S}_{\mathrm{a}} \mathrm{O}_{2 \mathrm{post}} \%$ & $89.19(86.50,91.30)$ & $92.75(91.30,94.04)$ & $1.450 \mathrm{E}^{-08}$ & 3.17 (2.15 to 4.37$)$ \\
\hline Lactate $_{\text {rest }^{\prime}} \mathrm{mmol} / \mathrm{L}$ & $1.19(0.99,1.67)$ & $1.09(0.88,1.45)$ & 0.23 & \\
\hline Lactate $_{\text {post' }} \mathrm{mmol} / \mathrm{L}$ & $1.90(1.50,2.62)$ & $1.85(1.14,2.40)$ & $4.134 \mathrm{E}^{-02}$ & $-0.135(-0.29$ to -0.005$)$ \\
\hline \multicolumn{5}{|l|}{ SenTec digital monitor } \\
\hline $\mathrm{SpO}_{2 \text { rest }} \%$ & $96.0(95.0,98.0)$ & $93.0(93.0,95.0)$ & $2.286 \mathrm{E}^{-11}$ & $-3(-3.5$ to -2.5$)$ \\
\hline $\mathrm{SpO}_{2 \text { isotime_100\% }} \%$ & $89.0(86.0,93.0)$ & $92.0(90.0,94.0)$ & $5.275 \mathrm{E}^{-04}$ & $3(1$ to 4$)$ \\
\hline $\mathrm{SpO}_{2 \mathrm{post} t^{\prime}} \%$ & $89.0(86.0,93.0)$ & $93.0(92.0,94.0)$ & $1.758 \mathrm{E}^{-04}$ & $3(1.5$ to 5$)$ \\
\hline $\mathrm{SpO}_{2 \min } \%$ & $88.0(85,91)$ & $87.5(83.0,89.0)$ & 0.05 & \\
\hline $\mathrm{SpO}_{2 \text { max }^{\prime}} \%$ & $97.0(96.0,99.0)$ & $95.0(94.0,96.0)$ & $1.122 \mathrm{E}^{-09}$ & $-2(-2.5$ to -1.5$)$ \\
\hline $\mathrm{SpO}_{2 \text { mean }} \%$ & $92.0(89.0,94.0)$ & $92.0(91.0,93.0)$ & 0.77 & \\
\hline Time to $\mathrm{SpO}_{2}<90 \%$, s & $\begin{array}{l}\mathrm{n}=32 \\
102.0(73.0,158.0)\end{array}$ & $\begin{array}{l}n=39 \\
55.0(19.0,74.0)\end{array}$ & $6.937 \mathrm{E}^{-06}$ & $-71.8(-101$ to -47$)$ \\
\hline Time to $\mathrm{SpO}_{2}<85 \%$, s & $\begin{array}{l}\mathrm{n}=11 \\
152.0(112.0,194.0)\end{array}$ & $\begin{array}{l}n=16 \\
81.5(61.0,137.5)\end{array}$ & 0.11 & \\
\hline $\mathrm{TcPCO}_{2 \text { rest' }} \mathrm{mm} \mathrm{Hg}$ & $43.0(39.8,46.1)$ & $42.6(39.4,46.3)$ & 0.19 & \\
\hline $\mathrm{TCPCO}_{\text {2isotime_100\%, }} \mathrm{mm} \mathrm{Hg}$ & $47.7(45.4,50.9)$ & $47.7(44.6,53.7)$ & 0.93 & \\
\hline $\mathrm{TcPCO}_{2 \text { post' }} \mathrm{mm} \mathrm{Hg}$ & $47.75(45.4,50.9)$ & $48.0(45.5,53.6)$ & 0.57 & \\
\hline $\mathrm{TCPCO}_{2 \mathrm{max}^{\prime}} \mathrm{mm} \mathrm{Hg}$ & $48.9(45.8,51.75)$ & $49.2(46.4,55.2)$ & 0.42 & \\
\hline Heart rate $_{\text {rest' }} \mathrm{b} / \mathrm{min}$ & $83.0(78.0,88.0)$ & $84.0(79.0,93.0)$ & $3.859 \mathrm{E}^{-02}$ & $2(0$ to 4.5$)$ \\
\hline Heart rate isotime_100\%, $_{1} \mathrm{~b} / \mathrm{min}$ & $100.5(95.0,106.0)$ & $100.5(95.0,108.0)$ & 0.17 & \\
\hline Heart rate $_{\text {post }} \mathrm{b} / \mathrm{min}$ & $101.0(95.0,107.0)$ & $103.0(96.0,112.0)$ & $4.381 \mathrm{E}^{-03}$ & $3.5(1$ to 5.5$)$ \\
\hline Heart rate $_{\text {max }}$, $/$ min & $104.5(99.0,116.0)$ & $106.0(99.0,117.0)$ & 0.06 & \\
\hline \multicolumn{5}{|l|}{ Respiratory rate } \\
\hline Respiratory rate $_{\text {rest }}, 1 / \mathrm{min}$ & $18.0(14.0,24.0)$ & $20(17.0,24.0)$ & $1.079 \mathrm{E}^{-03}$ & 2 (1 to 3.5$)$ \\
\hline Respiratory rate $_{\text {isotime_100\% }}, 1 / \mathrm{min}$ & $31.0(24.0,45.5)$ & $31.0(23.5,44.0)$ & 0.25 & \\
\hline Respiratory rate $_{\text {post' }} 1 / \mathrm{min}$ & $29.0(24.0,34.0)$ & $29.0(21.0,34.0)$ & 0.40 & \\
\hline \multicolumn{5}{|l|}{ Borg scale } \\
\hline Dyspnoea $_{\text {rest' }}$ points & $1.0(0.0,2.0)$ & $1.0(0.0,2.0)$ & 0.96 & \\
\hline Dyspnoea $_{\text {post }}$ points & $6.0(5.0,7.0)$ & $5.0(4.0,7.0)$ & $1.914 \mathrm{E}^{-04}$ & $-0.5(-1$ to -0.5$)$ \\
\hline Leg fatigue $_{\text {rest' }}$ points & $1.0(0.0,2.0)$ & $1.0(0.0,2.0)$ & 0.79 & \\
\hline Leg fatigue $_{\text {post }}$ points & $4.0(3.0,6.0)$ & $4.0(3.0,5.0)$ & 0.10 & \\
\hline
\end{tabular}

\footnotetext{
Differences with $p$ values $<0.01$ are presented in bold.
}

Note: Median effects are not necessarily medians of differences; ${ }^{x}$ non-parametric $2 \times 2$ crossover models based on Monte Carlo simulations using Wilcoxon (mid rank) test. P-values are unadjusted for multiple comparisons.

Data presented as median (IQR).

ATOS, automatically titrating oxygen system; $\mathrm{BE}$, base excess; $\mathrm{CFOS}$, constant flow oxygen system; ESWT, endurance shuttle walk test; $\mathrm{HCO}_{3^{\prime}}$, hydrogen carbonate; $\mathrm{O}_{2}$, oxygen; $\mathrm{PCO}_{2}$, partial pressure of carbon dioxide; $\mathrm{PH}_{\text {, }}$ potential of hydrogen; $\mathrm{PO}_{2}$, partial pressure of oxygen; $\mathrm{SaO}_{2^{\prime}}$ oxygen saturation measured by blood gas analyses; $\mathrm{SpO}_{2^{\prime}}$ oxygen saturation; $\mathrm{TcPCO}_{2^{\prime}}$, transcutaneous carbon dioxide. 
A

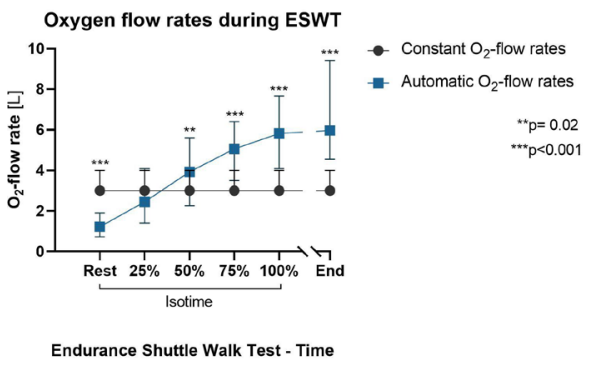

B

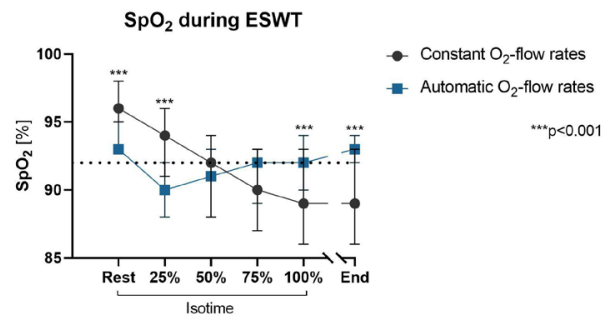

Endurance Shuttle Walk Test - Time

D

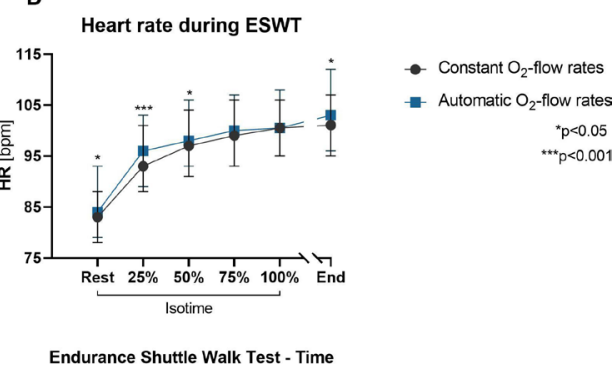

Figure 2 (A) Oxygen flow rates during the endurance shuttle walk test (ESWT). (B) Oxygen saturation ( $\mathrm{SpO}_{2}$ ) during ESWT. Dashed line at $92 \%$ $\mathrm{SpO}_{2}$. (C) Transcutaneous carbon dioxide (TCPCO $)$ during ESWT. Shaded area in grey between 45 and $55 \mathrm{~mm} \mathrm{Hg}$. (D) Heart rate (HR) during ESWT. Data is presented as median; error bars: IQR; $\mathrm{p}$ values were calculated via non-parametric $2 \times 2$ cross-over models based on Monte Carlo simulations using Wilcoxon (mid rank) test. P values are unadjusted for multiple comparisons.

participants perception and preference due to the $\mathrm{O}_{2}$-delivery systems during walking exercise.

\section{Exercise capacity}

Even using individually exercise titrated CFOS, the increase in walking distance with ATOS was comparable or even greater to that seen in previous studies with a resting-titrated or standardised CFOS (change in walking duration: $43 \%$ vs $33 \%{ }^{6}$ and $\left.17 \%{ }^{11}\right)$. This may be due to the greater number of participants in our study as well more being hypoxaemic at rest $\left(\mathrm{PO}_{2}: 54.7 \mathrm{vs}\right.$ $62^{6}$ and $72^{11} \mathrm{~mm} \mathrm{Hg}$ ) making the effects of supplemental oxygen potentially more consistent. ${ }^{16}$

No differences in lung function or anthropometric parameters were found between ATOS responders (change in walking duration $>$ MID) and non-responders. In our study, ATOS responders tended to have lower lactate values as well as less leg fatigue at ESWT $_{\text {AтоS }}$ end compared with non-responders (table 3). Further, while responders walked a significantly longer duration and reported less dyspnoea, a significantly higher average $\mathrm{O}_{2}$-flow rate with ATOS was used. We might assume that the higher airflow may have contributed to a reduced sensation of breathlessness, ${ }^{17}$ however, no correlation between $\mathrm{O}_{2}$-flow rates and dyspnoea was found.

In addition to an increased walking capacity in $68 \%$ of the study cohort, significantly fewer participants had to stop ESWT $_{\text {Aто口 }}$ due to dyspnoea. Possibly this could be due to a better correction of hypoxaemia during the later stages (from $100 \%$ isotime) of the ESWT with ATOS. It has been shown that acute $\mathrm{O}_{2}$-supplementation improves exercise performance by reducing ventilation, dynamic hyperinflation and the perception of dyspnoea ${ }^{318}$ and those effects were potentially greater with ATOS. Somfay et al showed that supplemental oxygen during exercise induced a dose-dependent improvement in endurance capacity and symptom perception, which they attributed to decreased hyperinflation and slower breathing pattern. ${ }^{19}$ Participants in our trial were also given increasing doses of oxygen as $\mathrm{SpO}_{2}$ declined during exercise, so we might expect similar changes, however, when comparing ATOS to CFOS, we saw similar 100\% isotime and end exercise respiratory rate. As inspiratory capacity was not measured in our study, we cannot report if a reduction in dynamic hyperinflation occurred.

\section{Oxygenation}

Oxygen saturation was superior at $100 \%$ isotime $(\Delta 3 \%)$ and at end exercise $(\Delta 3 \%)$ with ATOS compared with CFOS by a statistically and clinically relevant amount. ${ }^{20}$ Vivodtzev $e t$ al reported that minimum $\mathrm{SpO}_{2}$-values occurred with CFOS (CFOS: $83.6 \%$ vs ATOS: $89.5 \% ; \mathrm{p}<0.001)^{6}$ which is contrary to the present study where minimum $\mathrm{SpO}_{2}$-values during walking were comparable although a greater number of patients desaturated and the time to desaturation $\left(\mathrm{SpO}_{2}<90 \%\right)$ was significantly shorter with ATOS. Compared with Lellouche et al and Vivodtzev et al, individually titrated CFOS may have been better suited to the participants physiological needs during exercise ${ }^{611}$ However, as CFOS was exercise titrated in the present study, flows may have been greater than needed at rest which is confirmed by $\mathrm{SpO}_{2}$-profiles where a significantly higher $\mathrm{SpO}_{2}$ at rest and ESWT 25\% isotime with CFOS was seen compared with ATOS (figure 2). The decline in $\mathrm{SpO}_{2}$ at the beginning of walking with ATOS could indicate that the automatic increase in $\mathrm{O}_{2}$-flows were slower than the physiological decrease during early exercise. The lower $\mathrm{SpO}_{2}$ target used in the current trial $\left(92 \%\right.$ vs $\left.94 \%{ }^{611}\right)$ may have also slowed the response of ATOS compared with previous trials.

$\mathrm{CO}_{2}$ In clinical practice, increasing $\mathrm{O}_{2}$-flows in patients with hypercapnia has ongoing concerns due to the risk of hyperoxia-induced hypercapnia and is therefore regularly avoided. ${ }^{212}$ However, in agreement with $\mathrm{PCO}_{2}$ results observed by Lellouche et al, ${ }^{11}$ carbon dioxide levels measured via blood gas sample and transcutaneously were comparable between the two ESWTs, even 
Table 3 Subgroup analyses (ATOS responders vs non-responders) —results. Data presented as median (IQR)

\begin{tabular}{|c|c|c|c|c|}
\hline & Non-responder $(n=24)$ & Responder $(n=26)$ & P value ${ }^{\mathrm{x})}$ & $\begin{array}{l}\text { Median effect }(95 \% \mathrm{Cl}) \\
\text { responder-non-responder }\end{array}$ \\
\hline \multicolumn{5}{|l|}{ Baseline characteristics } \\
\hline $\mathrm{FEV}_{1}, \%$ predicted & $29.4(25.6,36.9)$ & $30.1(24.1,33.4)$ & 0.67 & \\
\hline $\mathrm{RV}, / \mathrm{TLC}, \%$ predicted & $182.8(168.0,203.0)$ & $199.3(178.7,209.6)$ & 0.18 & \\
\hline FRC, \% predicted & $207.7(176.5,240.3)$ & $228.7(188.5,252.7)$ & 0.42 & \\
\hline $\mathrm{PO}_{2}$-rest with room air, $\mathrm{mm} \mathrm{Hg}$ & $53.6(52.0,57.2)$ & $54.7(50.4,57.3)$ & 0.86 & \\
\hline $\mathrm{PCO}_{2}$-rest with room air, $\mathrm{mm} \mathrm{Hg}$ & $44.4(39.5,46.8)$ & $44.6(38.1,48.6)$ & 0.72 & \\
\hline $\mathrm{O}_{2}$ flow rate-exercise, $\mathrm{L} / \mathrm{min}$ & $3.5(3.0,4.0)$ & $3.0(2.5,4.0)$ & 0.42 & \\
\hline Age, years & $66.5(61.0,73.0)$ & $62.0(59.0,68.0)$ & 0.20 & \\
\hline $\mathrm{BMI}, \mathrm{kg} / \mathrm{m}^{2}$ & $24.3(21.3,26.4)$ & $23.7(21.3,26.1)$ & 0.45 & \\
\hline Waist circumference, $\mathrm{cm}$ & $96.5(89.5,107.0)$ & $89.5(83.0,100.5)$ & 0.13 & \\
\hline Waist-hip ratio & $0.97(0.89,1.0)$ & $0.91(0.86,0.98)$ & 0.14 & \\
\hline \multicolumn{5}{|l|}{ ESWT $_{\text {ATOS }}$} \\
\hline Mean $\mathrm{O}_{2}$-flow rate, $\mathrm{L}$ & $3.9(2.6,4.7)$ & $5.2(3.9,6.7)$ & $8.768 \mathrm{E}^{-03}$ & $1.6(0.49$ to 2.7$)$ \\
\hline Time, $\mathrm{s}$ & $280.0(199.0,857.0)$ & $751.5(419.0,1200.0)$ & $2.664 \mathrm{E}^{-03}$ & 268 (75 to 549$)$ \\
\hline Distance, $\mathrm{m}$ & $265.0(155.0,925.0)$ & $675.0(350.0,1210.0)$ & $1.287 \mathrm{E}^{-02}$ & 225 (50 to 530$)$ \\
\hline \multicolumn{5}{|l|}{ Blood gas analyses } \\
\hline $\mathrm{PO}_{\text {2rest' }} \mathrm{mm} \mathrm{Hg}$ & $65.4(62.7,67.9)$ & $65.1(61.0,68.6)$ & 0.75 & \\
\hline $\mathrm{PO}_{2 \text { post' }} \mathrm{mm} \mathrm{Hg}$ & $66.3(60.7,73.2)$ & $74.1(71.0,76.6)$ & $3.364 \mathrm{E}^{-03}$ & $7.25(2.4$ to 11.6$)$ \\
\hline $\mathrm{SaO}_{2 \text { rest' }} \mathrm{mm} \mathrm{Hg}$ & $93.1(91.4,93.7)$ & $92.9(91.7,93.3)$ & 0.62 & \\
\hline $\mathrm{SaO}_{2 \text { posst }} \mathrm{mm} \mathrm{Hg}$ & $91.8(88.9,93.7)$ & $93.5(92.0,94.2)$ & $4.141 \mathrm{E}^{-02}$ & 1.24 (0.04 to 2.8$)$ \\
\hline $\mathrm{PCO}_{\text {2rest' }} \mathrm{mm} \mathrm{Hg}$ & $40.8(39.9,47.0)$ & $41.8(39.0,48.3)$ & 0.74 & \\
\hline $\mathrm{PCO}_{2 \text { post' }} \mathrm{mm} \mathrm{Hg}$ & $48.3(46.2,53.6)$ & $51.6(48.6,56.1)$ & 0.23 & \\
\hline $\mathrm{Ph}_{\text {rest }}$ & $7.41(7.39,7.43)$ & $7.41(7.40,7.43)$ & 0.68 & \\
\hline $\mathrm{Ph}_{\text {post }}$ & $7.36(7.33,7.38)$ & $7.34(7.31,7.36)$ & 0.05 & \\
\hline Lactate $_{\text {rest, }} \mathrm{mmol} / \mathrm{L}$ & $1.2(1.0,1.6)$ & $1.0(0.8,1.2)$ & 0.14 & \\
\hline Lactate $_{\text {post }_{1}} \mathrm{mmol} / \mathrm{L}$ & $1.9(1.6,2.4)$ & $1.4(1.0,2.2)$ & 0.08 & \\
\hline \multicolumn{5}{|l|}{ Borg scale } \\
\hline Dyspnoea $_{\text {post' }}$ points & $6.0(4.0,7.5)$ & $5.0(4.0,5.0)$ & $1.107 \mathrm{E}^{-02}$ & $-1(-2$ to 0$)$ \\
\hline$\Delta$ Dyspnoea, points & $4.0(3.0,6.5)$ & $3.0(2.0,4.0)$ & $1.614 \mathrm{E}^{-03}$ & $-1(-2$ to 0$)$ \\
\hline Leg fatigue $_{\text {post' }}$ points & $6.0(4.0,7.5)$ & $4.0(3.0,5.0)$ & 0.35 & \\
\hline$\Delta$ Leg fatigue, points & $4.0(3.0,6.5)$ & $2.0(1.0,3.0)$ & 0.58 & \\
\hline
\end{tabular}

Differences with $\mathrm{p}$ values $<0.01$ are presented in bold. Note: Median effects are not necessarily medians of differences; ${ }^{\mathrm{x})}$ Mann-Whitney $\mathrm{U}$ test. $\mathrm{P}$ values are unadjusted for multiple comparisons.

ATOS, automatically titrating oxygen system; BMI, body mass index; ESWT, endurance shuttle walk test; FEV , forced expiratory volume in $1 \mathrm{~s}$; FRC, functional residual capacity; $\mathrm{PCO}_{2}$, partial pressure of carbon dioxide; $\mathrm{pH}$, potential of hydrogen; $\mathrm{PO}_{2^{\prime}}$ partial pressure of oxygen; $\mathrm{RV}$, residual volume; $\mathrm{SaO}_{2^{\prime}}$ oxygen saturation measured by blood gas analyses; TLC, total lung capacity.

with higher $\mathrm{O}_{2}$-flows from $50 \%$ isotime on with ATOS. When comparing ATOS-responders to non-responders, responders received on average $1.6 \mathrm{~L} / \mathrm{min}$ more oxygen with ATOS and mean $\mathrm{TcPCO}_{2}$ during walking was significantly higher. Overall, for both systems a significant correlation between change in $\mathrm{PCO}_{2}$ and the mean $\mathrm{O}_{2}$-flow was found.

\section{Exercise-induced hypercapnia}

Some patients with COPD, while normocapnic at rest, retain $\mathrm{CO}_{2}$ during increased activity and may develop exerciseinduced hypercapnia (EIH: defined as $\mathrm{PCO}_{2} \geq 45 \mathrm{~mm} \mathrm{Hg}$ post ESWT). ${ }^{23}$ To examine a possible difference in the effects between participants who were normocapnic at rest $\left(\mathrm{PCO}_{2}<45 \mathrm{~mm} \mathrm{Hg}\right.$ breathing room air; $\left.\mathrm{n}=27\right)$ and those who were hypercapnic at rest $\left(\mathrm{PCO}_{2} \geq 45 \mathrm{~mm} \mathrm{Hg}\right.$ breathing room air; $\mathrm{n}=23$ ) a subgroup analysis was performed (online supplemental table S3). We found, in the normocapnic subgroup, signs of EIH in $77.8 \%(n=21 / 27)$ of the participants with CFOS and $74.1 \%$ $(n=20 / 27)$ with ATOS. Development of EIH in both ESWTs was observed in $74.1 \%(n=20)$ of participants. This is greater than previously seen by Andrianopoulos et al where only $31 \%$ of participants developed EIH during a 6-minute walk test. ${ }^{25}$ This could be explained by participants being less hypoxaemic at rest with better lung function and only $79 \%$ having a prescription of $\mathrm{O}_{2}$ during exercise compared with $100 \%$ in the present study. ${ }^{25}$

In this study we developed a multivariable regression model to predict the $\mathrm{PCO}_{2}$ post walking exercise. As exercise-induced changes in $\mathrm{PCO}_{2}$ are highly dependent on several pathophysiological mechanisms in $\mathrm{COPD}^{23}$ the ability to predict the $\mathrm{PCO}_{2}$ post walking may help clinicians better select patients for ATOS. However, we suggest evaluating this in a larger sample in order to readjust the models and further improve accuracy. Of note, 
A

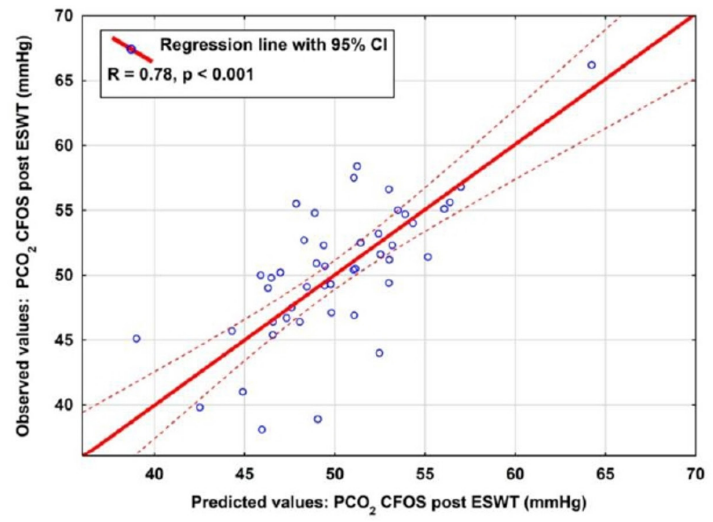

B

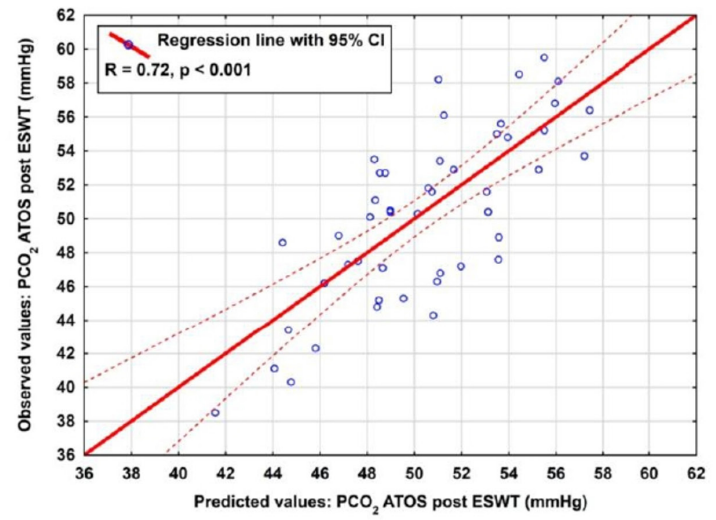

Figure 3 (A) Illustration of relation between observed and predicted $\mathrm{PCO}_{2}$ values $(\mathrm{mm} \mathrm{Hg})$ post endurance shuttle walk test (ESWT) with constant oxygen flows of the regression model. The model based on body mass index $(p=0.0002)$, waist circumference $(p=0.00008)$, residual volume in litres $(\mathrm{p}=0.008)$ and $\mathrm{PCO}_{2}$ at rest prior to walking test $(\mathrm{p}=0.00002)$. Multivariable regression model equation: $P C \mathrm{O}_{2}$ post walk predicted $=22.358+$ $1.325^{*}$ Body Mass Index $-0.395^{*}$ waist circumference $+1.382^{*}$ residual volume $+0.574{ }^{*} P \mathrm{CO}_{2}$ pre walking test. (B) Illustration of relation between observed and predicted $\mathrm{PCO}_{2}$ values $(\mathrm{mm} \mathrm{Hg})$ post ESWT with automatic oxygen flows of the regression model. The model is based on body mass index $(\mathrm{p}=0.011)$, waist circumference $(\mathrm{p}=0.028)$ and $\mathrm{PCO}_{2}$ in rest prior walking test $(\mathrm{p}=0.028)$. Multivariable regression model equation: $P C \mathrm{O}_{2}$ post walk predicted $=26.462+0.628{ }^{*} P \mathrm{PO}_{2}$ pre walking test $+0.693^{*}$ Body Mass Index $-0.203^{*}$ waist circumference. ATOS, automatically titrating oxygen system; CFOS, constant flow oxygen system; $\mathrm{PCO}_{2}$, partial pressure of carbon dioxide.

independent of $\mathrm{O}_{2}$-system, $\mathrm{PCO}_{2}$ was on average normocapnic pre-exercise (CFOS: $42.5 \mathrm{~mm} \mathrm{Hg}$; ATOS: $40.85 \mathrm{~mm} \mathrm{Hg}$ ) and was a median of $50.45 \mathrm{~mm} \mathrm{Hg}$ post exercise. This is reinforced by a moderate negative correlation between resting $\mathrm{PCO}_{2}$ and change in ESWT $\mathrm{PCO}_{2}$ showing participants with a lower starting $\mathrm{PCO}_{2}$ had the greatest changes during exercise. Simard et al found, that in some patients with COPD, EIH is a precursor to chronic hypercapnia. ${ }^{26}$ The large number of participants with $\mathrm{EIH}$ in the current study might underline the importance of observing $\mathrm{PCO}_{2}$-levels in patients with severe and very severe COPD during exercise to consider using other aids (eg, noninvasive ventilation). ${ }^{27} 28$

\section{Limitations}

Some limitations of the present study must be considered. Surprisingly, 14 patients reached the maximal exercise duration of $20 \mathrm{~min}$ with ATOS and 5 of those with CFOS also. Had this limit been longer, the effect size may have been different, however, given the present study reached an effect of statistical significance greater than the MID, the final outcome is unaffected. The ISWT was conducted once, but $90 \%$ of the participants did either not reach the maximum duration or reached it only in one test. We therefore assume, that in the majority of the study population the speed was appropriately chosen. Second the use of the 6-minute walk test to obtain an $\mathrm{O}_{2}$-titration is not optimal for an ESWT, however it is the practice suggested in clinical guidelines and is superior to using the same $\mathrm{O}_{2}$-flow for the entire group.

Further, this study demonstrates the immediate effects of $\mathrm{O}_{2}$ therapy during walking exercise and might not reflect longer usage scenarios or during different exercise modalities. Also of note, no adjustment for multiple comparisons was done on the familywise error, however, $\mathrm{p}$ values with high precision (in scientific notation) are presented for use in a correction such as a Bonferroni-Holm. Finally, the regression models are based on learning samples only and the generalisability of the models should be evaluated in independent validation data sets.
Current generation ATOS devices are limited though as they are large, assume an infinite $\mathrm{O}_{2}$-supply and rely completely on a finger sensor. Future studies should determine whether improved ATOS with faster $\mathrm{O}_{2}$-flow regulation have the potential to improve results. They should also focus on medium-term and long-term effects of using ATOS in exercise training or daily life as well as economic factors like $\mathrm{O}_{2}$-usage (eg, overall use during exercise training), device, maintenance and staff costs (eg, reduced number of $\mathrm{O}_{2}$-titration assessments). Further, other pathologies, such as interstitial lung disease ${ }^{29}$ or COVID-19 $9^{30}$ may desaturate in exercise and an ATOS could be a promising approach.

\section{CONCLUSION}

As shown by this randomised, double-blinded, crossover trial, we found that the use of an automatically titrating supplemental $\mathrm{O}_{2}$ system, capable of adjusting $\mathrm{O}_{2}$-flows during exercise in response to $\mathrm{SpO}_{2}$, leads to significantly and clinically relevant improvements in walking endurance time, oxygenation and dyspnoea compared with an individually, exercise titrated constant $\mathrm{O}_{2}$ flow system as commonly used in practice.

The clinical implications are that ATOS set to keep a $\mathrm{SpO}_{2}$ target of $92 \%$ in patients with hypoxaemia with severe and very severe COPD has an immediate positive effect on exercise capacity with no difference in $\mathrm{CO}_{2}$. This result disputes the 'one flow rate fits all' mentality for $\mathrm{O}_{2}$-supplementation during exercise and suggests that automatic systems may be a promising method for improved, individually tailored treatment. Finally, participants preferred an automatic $\mathrm{O}_{2}$-system over constant and future work should be invested in making a more portable version which reacts faster to changing $\mathrm{O}_{2}$-levels.

\section{Author affiliations}

'Department of Pulmonary Rehabilitation, Philipps-University of Marburg, Marburg, Hessen, Germany

${ }^{2}$ Institute for Pulmonary Rehabilitation Research, Schoen Klinik Berchtesgadener Land, Schoenau am Koenigssee, Germany

${ }^{3}$ Research Office (Biostatistics), Paracelsus Medical University Salzburg, Salzburg, Austria 
${ }^{4}$ Department of Ophthalmology and Optometry, Paracelsus Medical University Salzburg, Salzburg, Austria

${ }^{5}$ Research Program Experimental Ophthalmology and Glaucoma Research, Paracelsus Medical University Salzburg, Salzburg, Austria

${ }^{6}$ Faculty of Medicine and Health, The University of Sydney, Sydney, New South Wales, Australia

${ }^{7}$ Medical School, Philipps-University of Marburg, Marburg, Hessen, Germany

${ }^{8}$ Department of Sleep and Respiratory Medicine, Evangelical Hospital Goettingen-

Weende, Bovenden, Germany

${ }^{9}$ German Center for Lung Research (DZL), Universities of Giessen and Marburg Lung

Center, Giessen, Hessen, Germany

${ }^{10}$ Teaching Hospital, Paracelsus Medical University Salzburg, Salzburg, Austria

Acknowledgements Consumable materials for the SenTec device were kindly supported by SenTec AG. SenTec AG had no influence on the study design, execution or analyses.

Contributors TS, KK and IJ conducted the study design. TS, DL, TG, IJ and RG performed the data collecting. WH and TS performed the data analyses. TS prepared the manuscript. KK, CJD, C-PC, ARK, IJ, WH, RG, DL, TG and TS critically revised the manuscript. All authors have read and approved the manuscript. TS takes the responsibility for the integrity.

Funding The authors have not declared a specific grant for this research from any funding agency in the public, commercial or not-for-profit sectors.

Competing interests None declared.

Patient consent for publication Not applicable.

Ethics approval The study was approved by an Ethic Committee (PhilippsUniversity of Marburg).

Provenance and peer review Not commissioned; externally peer reviewed.

Data availability statement Data are available upon reasonable request. Because of a data privacy statement in the ethics proposal, general raw data sharing is not permitted. The study protocol and informed consent form (German language) can be shared.

Open access This is an open access article distributed in accordance with the Creative Commons Attribution Non Commercial (CC BY-NC 4.0) license, which permits others to distribute, remix, adapt, build upon this work non-commercially, and license their derivative works on different terms, provided the original work is properly cited, appropriate credit is given, any changes made indicated, and the use is non-commercial. See: http://creativecommons.org/licenses/by-nc/4.0/.

\section{REFERENCES}

1 Branson RD. Oxygen therapy in COPD. Respir Care 2018;63:734-48.

2 Hardinge M, Annandale J, Bourne S, et al. British thoracic Society guidelines for home oxygen use in adults. Thorax 2015;70 Suppl 1:i1-43.

3 O'Donnell DE, D'Arsigny C, Webb KA. Effects of hyperoxia on ventilatory limitation during exercise in advanced chronic obstructive pulmonary disease. Am J Respir Crit Care Med 2001;163:892-8.

4 Global Strategy for the Diagnosis, Management, and Prevention of Chronic Obstructive Pulmonary Disease - 2020 Report, 2020. Available: https://goldcopd. org/wp-content/uploads/2019/12/GOLD-2020-FINAL-ver1.2-03Dec19_WMV.pdf [Accessed 27 May 2020].

5 et alHaidl P, Jany B, Geiseler J. Guidelines for long-term oxygen therapy S2k-Guideline published by the German respiratory Society, 2020. Available: https://www.awmf. org/uploads/tx_szleitlinien/020-002I_S2k_Langzeit_Sauerstofftherapie_2020-08.pdf [Accessed 02 Nov 2020].

6 Vivodtzev I, L'Her E, Vottero $\mathrm{G}$, et al. Automated $\mathrm{O}_{2}$ titration improves exercise capacity in patients with hypercapnic chronic obstructive pulmonary disease: a randomised controlled cross-over trial. Thorax 2019;74:298-301.

7 Sliwiński P, Lagosz M, Górecka D, et al. The adequacy of oxygenation in COPD patients undergoing long-term oxygen therapy assessed by pulse oximetry at home. Eur Respir J 1994;7:274-8.
8 Morrison D, Skwarski KM, MacNee W. The adequacy of oxygenation in patients with hypoxic chronic obstructive pulmonary disease treated with long-term domiciliary oxygen. Respir Med 1997;91:287-91.

9 Jarosch I, Gloeckl R, Damm E, et al. Short-Term effects of supplemental oxygen on 6-Min walk test outcomes in patients with COPD: a randomized, placebo-controlled, single-blind, crossover trial. Chest 2017;151:795-803.

10 Abdo WF, Heunks LMA. Oxygen-induced hypercapnia in COPD: myths and facts. Crit Care 2012;16:323.

11 Lellouche F, L'Her E, Bouchard P-A, et al. Automatic oxygen titration during walking in subjects with COPD: a randomized crossover controlled study. Respir Care 2016;61:1456-64.

12 Singh SJ, Puhan MA, Andrianopoulos V, et al. An official systematic review of the European respiratory Society/American thoracic Society: measurement properties of field walking tests in chronic respiratory disease. Eur Respir J 2014;44:1447-78. doi:10.1183/09031936.00150414

13 Lellouche F, L'her E. Automated oxygen flow titration to maintain constant oxygenation. Respir Care 2012;57:1254-62.

14 Lellouche F, Bouchard P-A, Roberge M, et al. Automated oxygen titration and weaning with FreeO2 in patients with acute exacerbation of COPD: a pilot randomized trial. Int J Chron Obstruct Pulmon Dis 2016;11:1983-90.

15 Borg G. Perceived exertion as an indicator of somatic stress. Scand I Rehabil Med 1970;2:92-8.

16 Ameer F, Carson KV, Usmani ZA. Ambulatory oxygen for people with chronic obstructive pulmonary disease who are not hypoxaemic at rest. Cochrane Database Syst Rev 2014;2014:CD000238. doi:10.1002/14651858.CD000238.pub2

17 Swan F, Newey A, Bland M, et al. Airflow relieves chronic breathlessness in people with advanced disease: an exploratory systematic review and meta-analyses. Palliat Med 2019:33:618-33.

18 Maltais F, Simon M, Jobin J, et al. Effects of oxygen on lower limb blood flow and 02 uptake during exercise in COPD. Med Sci Sports Exerc 2001;33:916-22.

19 Somfay A, Porszasz J, Lee SM, et al. Dose-response effect of oxygen on hyperinflation and exercise endurance in nonhypoxaemic COPD patients. Eur Respir J 2001:18:77-84

20 Stoller JK, Panos RJ, Krachman S, et al. Oxygen therapy for patients with COPD: current evidence and the long-term oxygen treatment trial. Chest 2010;138:179-87. doi:10.1378/chest.09-2555

21 Aubier M, Murciano D, Fournier M, et al. Central respiratory drive in acute respiratory failure of patients with chronic obstructive pulmonary disease. Am Rev Respir Dis 1980;122:191-9.

22 Aubier M, Murciano D, Milic-Emili J, et al. Effects of the administration of 02 on ventilation and blood gases in patients with chronic obstructive pulmonary disease during acute respiratory failure. Am Rev Respir Dis 1980;122:747-54.

23 O'Donnell DE, D'Arsigny C, Fitzpatrick $M$, et al. Exercise hypercapnia in advanced chronic obstructive pulmonary disease: the role of lung hyperinflation. Am J Respir Crit Care Med 2002;166:663-8.

24 Light RW, Mahutte CK, Brown SE. Etiology of carbon dioxide retention at rest and during exercise in chronic airflow obstruction. Chest 1988;94:61-7.

25 Andrianopoulos V, Vanfleteren LEGW, Jarosch I, et al. Transcutaneous carbon-dioxide partial pressure trends during six-minute walk test in patients with very severe COPD. Respir Physiol Neurobiol 2016;233:52-9.

26 Simard AA, Maltais F, LeBlanc P. Functional outcome of patients with chronic obstructive pulmonary disease and exercise hypercapnia. Eur Respir J 1995:8:1339-44

27 Gloeckl R, Andrianopoulos V, Stegemann A, et al. High-pressure non-invasive ventilation during exercise in COPD patients with chronic hypercapnic respiratory failure: a randomized, controlled, cross-over trial. Respirology 2019;24:254-61.

28 Menadue C, Piper AJ, van 't Hul AJ. Non-invasive ventilation during exercise training for people with chronic obstructive pulmonary disease. Cochrane Database Syst Rev 2014:5:CD007714. doi:10.1002/14651858.CD007714.pub2

29 Lama VN, Flaherty KR, Toews GB, et al. Prognostic value of desaturation during a 6-minute walk test in idiopathic interstitial pneumonia. Am J Respir Crit Care Med 2003;168:1084-90

30 Spruit MA, Holland AE, Singh SJ, et al. COVID-19: interim guidance on rehabilitation in the hospital and Post-Hospital phase from a European respiratory Society and American thoracic Society-coordinated international Task force. Eur Respir J 2020. doi:10.1183/13993003.02197-2020. [Epub ahead of print: 13 Aug 2020]. 